\title{
Conversos y judíos en tiempos de la expulsión: Un análisis crítico de investigación y análisis
}

\author{
S. HALICZER
}

A mediados de la década de los sesenta, los historiadores alcanzaron un amplio consenso respecto de los elementos clave de la vida de conversos y judíos en España durante los años que culminaron con la expulsión del 31 de marzo de 1492. Eruditos como Tarsicio de Azcona - cuya Isabel la Católica se publicó en 1964-miraban a los judíos como irremediablemente hostiles al cristianismo, tanto que ocasionalmente se habrían comprometido en directas blasfemias, burlándose de los rituales y las instituciones del catolicismo romano y uprofanando los sacramentos de la Iglesia, especialmente la eucaristía». A pesar de su obvia erudición, Azcona llega tan lejos como para aceptar la validez del infame libelo de la sangre del así llamado «Sagrado Niño de La Guardia». El libelo de la sangre es también aceptado como válido por Julio Caro Baroja, quien, en el primer volumen de Los judíos en la España moderna y contemporánea, lo hace equivaler casualmente a la misa negra, como algo efectiva y ocasionalmente realizado por razones mágicas, pero que nunca se correspondió con las enseñanzas o a la práctica general de la Iglesia. De la misma manera, el sacrificio del niño puede ser aceptado como la aberración de unos individuos supersticiosos, sin ser típica de los judíos y sin formar parte de las enseñanzas del judaísmo mismo ${ }^{1}$. Si sumamos la usura y el terco rechazo de los judíos a pagar impuestos a la blasfemia y a la muerte ritual, no es difícil ver por qué Azcona describe a los judíos como tan impopulares entre las masas de viejos cristianos que, una vez emitido el decreto, los Reyes Católicas sabian que sería recibido con «insuperable alegría” por el pueblo? .

Caro Baroja, Julio, Los judios en la España moderna y contemporánea, 3 vols. Madrid, Ediciones Arión, 1962, 1:171.

2 AzCONA, Isabel, 639. 
En lo que concierne a los conversos, los investigadores tienen pocas dificultades en asimilarlos a los judíos. Al discutir el período justo antes de la expulsión, Caro Baroja hace una pausa para comentar la «obstinación" conque los conversos mantenían su fe y sus costumbres, y la forma en que esta terquedad engendró la hostilidad de los viejos cristianos. El judío seguía siendo judío: el viejo cristiano continuó discriminando en contra de los conversos insistiendo en la pureza de su linaje y de su fe religiosa, y recordándoles sus vergonzosos orígenes a estos últimos en cuanta ocasión se le presentaba ${ }^{3}$. Este trabajo es un intento de revisión crítica de la literatura más reciente acerca de las relaciones entre judíos y viejos cristianos, y de examinar los puntos de vista asumidos por la anterior generación de historiadores acerca de las creencias religiosas de los conversos y la relación entre judíos y conversos en el período anterior a la expulsión. También adelantaré algunas sugerencias y daré ejemplos acerca de cómo una aproximación interdisciplinaria a cierto tipo de documentos puede producir una rica cosecha de interpretaciones y de penetración en las relaciones sociales en vísperas de la expulsión. Es de esperar que esta revaluación ayude a formular una nueva síntesis que provea una comprensión más ricamente matizada de estos fenómenos sociales extremadamente complejos y abra el camino para la investigación adicional de fuentes hasta ahora no totalmente utilizadas o incomprendidas.

Ai encarar el tema de las relaciones entre judíos y viejos cristianos, tenemos que hacernos a nosotros mismos algunas preguntas clave que fueron ampliamente ignoradas por la anterior generación de historiadores. En primer lugar, aunque podamos coincidir con aquéllos que, como Tarsicio de Azcona, aseguran que los judíos eran generalmente impopulares entre las masas de viejos cristianos en los tiempos de la expulsión, no todos los viejos cristianos dieron la bienvenida o apoyaron las leyes antisemitas o la misma expulsión. Un estudio de la comunidad judía del pueblo de Sos del Rey Católico (Alto Aragón), publicado en 1972 por José Cabezudo Astrain, indica que los judíos y los cristianos colaboraron en numerosos asuntos de negocios y trabajaron muy cerca unos de otros para ganarse el sustento en los viñedos y en los campos de lino y trigo que ambos poseían ${ }^{4}$. De la misma manera, Enrique Mirambell Belloc nos informa que la población de viejos cristianos de Gerona estaba lejos de estar contenta con la remoción de los judíos, con los cuales coexistía

3 Caro Baroja, los judios, 149

4 Cabezudo Astraín, José, "La judería de Sos del Rey Católico", Sefarad 32 (1972), 94. 
pacíficamente $^{5}$. El duque de Cardona —catalán-y otros magnates intentaron proteger a sus judios y supusieron que ellos no se verian afectados por la orden de expulsión puesto que no eran vasallos reales. En la ciudad de Ávila, que contenía la mayor comunidad judía de Castilla, las relaciones entre viejos y nuevos cristianos fueron buenas hasta el comienzo de la década de 1490 . Si la hostilidad no era universal y la vieja convivencia pudo (y efectivamente lo hizo) sobrevivir en algunos lugares, tenemos que preguntarnos qué elementos nuevos entraron a formar parte de la situación en la que se encontraron los judios durante el reinado de Fernando e Isabel que puedan haber engendrado una creciente hostilidad y en qué grado estos elementos eran el producto de una política consciente de parte del gobierno real.

Estudios recientes sobre el reino de Fernando e Isabel por Marvin Lunenfeld y otros han demostrado que durante los años de la Guerra de Sucesión y algún tiempo después siguieron una política destinada a ganar apoyo entre las masas populares, tanto de la ciudad cuanto del campo, contra algunos miembros de la alta nobleza que habían apoyado las pretensiones de Alfonso $\mathrm{V}$ de Portugal. Un resultado tangible de esta política fue la creación de la Santa Hermandad, una especie de milicia popular que no sólo cumplió funciones de policía en la campaña sino que también ofreció a Fernando e Isabel un significativo apoyo militar durante el conflicto en el marquesado de Villena y luego en la guerra de Granada ${ }^{6}$. Frente a un Tesoro casi vacío, una costosa guerra civil y con la esperanza de evitar una discusión abierta acerca de su favoritismo respecto de ciertos miembros de la nobleza, Fernando e Isabel buscaron ganar apoyo recurriendo al antisemitismo popular. Ya en 1475, cuando una severa sequía azotó a Castilla la Vieja, al norte de Palencia, Fernando ordenó la suspensión de todos los pagos que los campesinos debían realizar a los judíos prestamistas del área. Al mismo tiempo, el nuevo confesor de Isabel, el converso Fernando de Talavera, urgía a la población de la región a redoblar sus esfuerzos para ganar el favor divino haciendo procesiones a los santuario más conocidos y ordenó que todos se confesasen y comulgasen dentro de los 30 días. También denunciaba algunos abusos, la laxitud de las costumbres que había irritado a Dios, como el juego y la blasfemia, y los urgía a evitar el contacto con los infieles, es decir principalmente con los judíos?.

\footnotetext{
5 Mirambell Belloc, Enrique, "Los judíos gerundenses en el momento de la expulsión», Anales del Instituto de Estudios Gerundenses, 24 (1978), 7.

- Lunenfeld, Marvin, The Council of the Santa Hermandad (Coral Gables: University of Miami Press, 1970) and HALICZER, Stephen, The Comuneros of Castile: The forging of a Revolution 1745-1721 (Madison, The University of Wisconsin Press, 1981).

7 Azcona, Isabel, 228.
} 
El año siguiente, en las Cortes de Madrigal, donde se había establecido la Santa Hermandad, Fernando e Isabel dieron un decisivo paso adelante en el juego de la carta antisemita al aprobar leyes que limitaban los pagos de interés por créditos a un máximo del 30 por 100 y forzaban a los judíos acusados de haber excedido este límite a presentar dos testigos cristianos que juraran que no lo habían hecho, al mismo tiempo que otorgaban a las cortes eclesiásticas jurisdicción sobre la usura. El resultado natural de esta ley fue abrir las compuertas a una oleada de juicios iniciados por viejos cristianos que deseaban salvarse del repago de créditos a los prestamistas judíos. Este fenómeno ha sido extremadamente bien catalogado en la reciente disertación doctoral de Fernández Suárez Bilbao titulada "Judíos castellanos entre 1432 y 1492, ensayo de una prosopografía", que detalla cientos de juicios durante el período que culmina con la expulsión ${ }^{8}$. Obviamente, este tipo de litigio era muy costoso para ambas partes y tendía a empeorar significativamente las relaciones entre judíos y viejos cristianos, terminando en insultos raciales y en un nivel ascendente de violencia física. Abraham Harache, de Aguilar del Campo, fue un prestamista y cobrador de impuestos que tuvo que defenderse ocho veces en juicios entre 1486 y 1489, y en 1487 fue acusado de haber insultado la imagen de la virgen ${ }^{9}$. Un observador contemporáneo, Salomón ibn Verga, representante general de los judíos de Castilla y Aragón, culpó al conflicto originado por los préstamos de haber incrementado significativamente las tensiones entre judíos y viejos cristianos en los años previos a la expulsión.

Otra de las metas de la primera parte del reinado de Fernando e Isabel fue la promoción de la asimilación de los conversos. El método elegido fue la segregación forzada de los judíos respecto de la comunidad cristiana, de tal manera de reducir fuertemente su influencia sobre los conversos. Esta medida, muy favorecida por los principales partidarios de la asimilación de los conversos, comenzó temprano: en diciembre de 1477 , Fernando ordenó la segregación de los judíos de Soria, que fue seguida por la remoción a un barrio separado de Cáceres, en 1478. Finalmente, en las Cortes de Toledo de 1480, se sancionó legislación -bajo instigación real- para aplicar la política segregacionista a todos los judíos de Castilla y se mandaron comisionados para establecer los límites de los nuevos guetos. Como lo señalé en un artículo previo, el proceso de "guetisación» fue un severo golpe para la viabilidad económica de la co-

\footnotetext{
SuÁrez BILBAO, Fernando, «Judíos castellanos entre 1432 y 1492, ensayo de una prosopografía» (Ph. D. diss. Universidad Autónoma de Madrid, 1990).

SUÁREZ BILBAD, «Judíos Castellanos», 33.
} 
munidad judía, pero también constituyó lo que sociólogos y antropólogos Ilaman un «ritual de exclusión», por medio del cual un grupo entero era escogido especialmente para recibir un tratamiento negativo por parte de la comunidad. El fenómeno de la exclusión ha sido aplicado recientemente a la sociedad española moderna temprana en un libro editado por Agustín Redondo, Les problemes de l'exclusion en Espagne. En este caso, por orden del gobierno, los judíos fueron forzados a dejar las casas donde habían vivido durante generaciones y reubicados en áreas menos deseables, lejos del centro, o incluso en algunos casos, en barrios donde nadie quería vivir, donde fueron encerrados detrás de paredes y puertas, con acceso restringido al resto de la población urbana. Es fácil imaginar cómo la «guetisación», combinada con la sanción de la ley suntuaria restrictiva aprobada por las Cortes de Madrigal que insistía en que los judíos llevaran una señal distintiva, estigmatizaba a los judíos y los transformaba de un grupo que era aceptado, aunque de manera reacia, como una parte de la vida urbana, en un grupo desviado y efectivamente al margen de la sociedad urbana. No hay evidencia que sugiera que la política de segregación fue parte de un plan premeditado que condujo a la expulsión. La segregación fue una decisión política y en otros aspectos la Corona continuó su política proteccionista, interviniendo fuertemente para proteger a los judíos de los excesos de sus propios comisionados, que a veces fijaban unos límites demasiado estrechos para el nuevo gueto, pero desde un punto de vista sicosocial la segregacuón fue el comienzo de la exclusión y la expulsión. Hay aquí ciertamente una instancia en la cual la aplicación de categorías tomadas de la sociología de la desviación desarroIlada por sociólogos como Kai Erickson y Harold Garfinkle ayudan al historiador a comprender el proceso social que condujo a la expulsión ${ }^{10}$. Al contrario de la Corona, cuyas políticas condujeron a un no buscado incremento del sentimiento antisemita, la Inquisición deliberadamente buscó crear y mantener una ola de antisemitismo popular que apoyaría la expulsión de los judíos. En los sermones predicados por los inquisidores al abrir sus procedimientos en un área dada, alertan al público en general contra la presencia de herejía entre ellos. Cuando estas herejías terminan refiriéndose a las prácticas judías, dichas prácticas son estigmatizadas como el mal y no fue difícil para el público establecer la conexión entre la continuada presencia de judíos practicantes y la persistencia de la he-

10 Para una excelente introducción a la literatura sociológica de la desviación, ver ERICKSON, T., Wayward Puritans: a Study in the Sociology of Deviance (New York, John Wiley, 1966). Para la degradación de los individuos, ver GARFINKEL, HAROLD, "Conditions of Successful Degradations Ceremonies», American Journal of Sociology 61 (marzo 1956), 420-424. 
rejía, especialmente cuando los registros de los procesos revelan una interacción entre judíos y conversos.

En 1490-1491, la Inquisición buscó demostrar la íntima conexión entre la continuada presencia de la judería española y la herejía de los conversos utilizando el libelo de la sangre, una de las más fantásticas y efectivas invenciones del antisemitismo antiguo y medieval. A pesar del hecho de que los sacrificios de sangre están expresamente prohibidos por la Torah y que las prácticas judías de matanza y la ley de salado de la carne están destinadas a conseguir que quede la menor cantidad posible de sangre en los alimentos, las supersticiones paganas y cristianas sobre el poder sobrenatural y curativo de la sangre humana y las creencias populares acerca de la hostilidad de los judíos respecto de los cristianos condujeron a repetidos alegatos de que los judíos mataban a no-judíos para obtener sangre para la Pascua hebrea u otros rituales. El libelo de la sangre condujo a juicios y masacres de judíos en la Edad Media en Norwich (1114), Lincoln (1255), Blois (1171) y Zaragoza (1182). En la generación anterior a la expulsión, Alonso de Espina, un fraile franciscano confesor de Enrique IV, hizo muchos de estos cargos en su abiertamente antisemita tratado Fortalitium fidei contra judaeos, escrito en 1458 y publicado en $1460^{11}$.

El caso del así llamado «Niño Sagrado de La Guardia» comenzó en una forma que trae reminiscencias de la caza de brujas de comienzos del siglo $\varkappa \mathrm{VII}$, con las acciones arbitrarias del juzgado de primera instancia, que no respetó las reglas de procedimiento e hizo un uso liberal de la tortura. En junio de 1490, el vicario episcopal de Astorga ordenó el arresto de un converso llamado Benito García y lo acusó de llevar una hostia consagrada en su saco. Bajo repetida tortura, García implicó a seis judíos y cinco conversos de los pueblos de La Guardia y Tembleque en un complot fantástico que combinaba un corazón humano y un hostia consagrada en una poción mágica lo suficientemente fuerte como para causar la destrucción de la Inquisición primero y de todos los cristianos después $^{12}$.

Dadas las notorias inconsecuencias del proceso judicial, el hecho de que ninguna familia del distrito de Toledo donde el alegado crimen había

\footnotetext{
11 KAMEN, Henry, Inquisition and Society in Spain (Bloomington, Indiana University Press, 1985) 24.

i2 Haliczer, Stephen, «The Jew as Witch: Displaced Aggression and the Myth of the Santo Niño de La Guardia" en Mary Elizabeth Perry y Anne J. Cruz eds. Cultural encounters: The Impact of the Inquisition in Spain and the New World (Los Angeles, University of California Press, 1991) 147.
} 
sido cometido se presentara a reclamar el niño perdido y el curioso hecho de que el inquisidor general Tomás de Torquemada transfiriera el caso del tribunal de Toledo, establecido en 1485, a Ávila, donde las relaciones entre judíos y viejos cristianos eran relativamente calmas, es difícil evitar el sentimiento de que el caso del «Santo Niño» fue el de un juicio ejemplar destinado a incitar la animosidad hacia los judíos, en el que el veredicto está arreglado y se extrae una confesión pública. El aspecto ejemplarizador del caso se acentúa más con la inclusión de Álvaro de Santisteban, el corregidor real, en la consulta de fe que votó la sentencia final ${ }^{13}$. Este fue un procedimiento sin precedentes y, según mi conocimiento, nunca fue repetido en la historia del Santo Oficio. Las inconsistencias durante el juicio, la completa ausencia de corpus delicti y el uso liberal de la tortura invalidan la aceptación del caso del Santo Niño por parte de Azcona. Igualmente dudoso, a la luz de la investigación en curso sobre la Inquisición, es su afirmación de que la «Inquisición no sacó todo el caso de su manga»s ${ }^{14}$. La actuación de la Inquisición española deja mucho que desear en el área de los procedimientos judiciales y eran frecuentes las deficiencias de la justicia, incluso según los estándares del mismo tribunal. El más obvio ejemplo de esto fue que los inquisidores de Logroño aceptaron los alegatos de brujería hechos contra cientos de vascos, que dieron como resultado el auto de fe del 7 de noviembre de 1610, en el cual fueron quemadas seis personas. Este procedimiento no sólo violaba la cauta aproximación de la Inquisición a las acusaciones de brujería adoptada desde mediados de la década de 1520 , sino que fue invalidada por la famosa visita de Alonso de Salazar Frías en 1611-1612. Para la discusión de este caso hay que ver Gustav Henningsen, The withces' Advocate, Basque Witchcraft and the Spanish Inquisition ${ }^{15}$. En cuanto a la comparación de Caro Baroja de este caso con la misa negra entre los cristianos, parece haber escasas razones para imputar supersticiones cristianas acerca del mágico poder de la sangre y de la hostia consagrada a los judíos, que no compartían dicha creencia. Pero esto es justo lo que tendríamos que admitir si los cargos contra el acusado fueran ciertos. La estrecha conexión entre el catolicismo romano y las supersticiones sobre la sangre y la hostia, así como también otra varias, han sido tratadas extensamente en Keith Thomas, Religion and the Decline of Magic, $19711^{16}$.

\footnotetext{
13 Lunenfeld, Marvin, Keepers of the City: The Corregidores of Isabel I of Castille, (Cambridge, Cambridge University Press, 1987) 131.

14 AzCONA, Isabel, 638.

15 Henningsen, Gustav, The Witches' Advocate: Basque Witchraft and the Spanish Inquisition (Reno, University of Nevada Press, 1980)

16 Thomas, Keith, Religion and the Decline of Magic (Harmondsworth, Penguin, 1971).
} 
Lo que podemos decir es que si exacerbar las tensiones entre judíos y viejos cristianos en la hasta entonces pacífica ciudad de Ávila fue el objetivo de la Inquisición, ciertamente tuvieron éxito. Después de anunciado el veredicto, los viejos cristianos comenzaron a apedrear judíos en las calles y la Corona se vio forzada a tomar a la comunidad bajo protección real ${ }^{17}$. La significación del caso del Santo Niño en la creación del clima de histeria que rodeó la expulsión y desembocó en ataques armados contra los judios mientras partían a los puertos de embarque fue debidamente notada por observadores posteriores. Fray Luis Ariz, historiador de Ávila de comienzos del siglo xvII, llanamente declara que «fue por su crucifixión del niño y su abuso de la hostia que los judíos se vieron forzados a dejar España» ${ }^{18}$.

Los deliberados esfuerzos de la Inquisición para crear un clima de hostilidad hacia la continuada presencia de los judíos fueron decididamente secundados por las órdenes mendicantes. Puesto que todos los primeros inquisidores eran dominicos o franciscanos, resulta tentador considerar a la Inquisición durante este período como la extensión institucional del tradicional antisemitismo mendicante. Entre los más fanáticos se encontraba el franciscano Luis de Santa Cruz, que denunció a los judíos de Zaragoza en una serie de inflamados sermones en 1479. En 1485, Abraham Senior, el juez supremo de todas las aljamas judías de Castilla, denunció al dominico Antonio de la Peña ante el Consejo Real por azúcar al pueblo de Segovia contra la comunidad judía local ${ }^{19}$. En Medina del Campo, cuando el corregidor real Francisco de Luzón accedió a permitir a los judíos locales la apertura de negocios en la plaza central, los franciscanos protestaron tan intensamente que el Consejo Real tuvo que revertir su decisión ${ }^{20}$. Finalmente, después que se anunció la orden de expulsión, el cronista Bernáldez nos informa que las sinagogas fueron literalmente invadidas por monjes franciscanos y dominicos que trataban de convertir a los judíos ${ }^{21}$.

Desde esta perspectiva, parece que la hostilidad popular en contra de los judios en los años inmediatamente anteriores a la expulsión no fue,

17 SuÁaEz Fernández, Luis, Documentos acerca de la expulsión de los judíos (Valladolid, CSIC, 1964) 381-382.

18 ARIz, Fray Luis, Historia de las grandezas de la ciudad de Ávila (Alcalá de Henares, Luis Martínez Grande, 1607) 47.

19 KrIegel, M., "La prise d'une décision: l'expulsion des juifs d'Espagne en 1492", Revue Historique cclx, 1 (1978) 54.

20 LUNENFELD, Keepers of the City 128-129.

21 Bernáldez, Alonso, Crónica de los Reyes Católicos Don Fernando y Doña isabel, Biblioteca de Autores Españoles, LXX (1953), 252. 
estrictamente, un producto de su inconfọmismo religioso, como implica Azcona. Los judíos siempre han sido diferentes en exactamente la misma forma. Siempre han «dicho sus plegarias en hebreo, celebrado el Sabbath y trabajado en domingo o en los días sagrados de los cristianos». De cualquier manera, la agitación popular en contra de los judíos había disminuido durante el siglo xv tardío, mientras que la hostilidad de los viejos cristianos se dirigía principalmente contra los conversos. Menos todavía fue el resultado de «una casi biológica incompatibilidad-o de «las leyes misteriosas que gobiernan la historia de los movimientos de masas", como afirma Azcona ${ }^{22}$. En lugar de esto, lo que hemos tratado de sugerir aquí es que el afloramiento del antisemitismo popular corresponde a factores muy concretos, que incluyen los indeseados resultados de la política real pensada para ganar apoyo político entre las masas populares y la creación intencional de un clima de histeria masiva y fervor religioso por parte de la Inquisición y las órdenes mendicantes. Es perfectamente consistente con este punto de vista para la Inquisición, al menos, la expulsión significó aumentar su importancia política. En Zaragoza, por ejemplo, Miguel Ángel Motis Dolader nos informa que los delegados de la Corona y los delegados de la Inquisición actuaban en plano de igualdad en las comisiones responsables del secuestro de propiedades judías. Al mismo tiempo, los judíos eran puestos bajo la restricción de la Inquisición si no cooperaban con las comisiones. En un ejemplo más de la completa distorsión de las leyes inquisitoriales, los judíos, que no podrían haber sido nunca considerados heréticos porque nunca fueron cristianos, fueron llevados a juicio como «relapsos» heréticos y defensores de heréticos si ocultaban su capital $^{23}$.

Uno de los elementos clave de que la historiografía anterior utilizó para justificar el establecimiento de la Inquisición Nacional Española fue la intransigente posición religiosa de los conversos. Según Azcona, los conversos eran «psicológicamente incapaces» de abandonar su antigua religión y de esta manera constituían una seria amenaza a la uniformidad religiosa de España ${ }^{24}$. En la segunda parte de esta presentación quiero examinar críticamente esta generalización confiada y sugerir que hasta muy recientemente los investigadores han tendido a caer en una forma de pensamiento inquisitorial, aceptando la asunción fundamental de la Inquisición de que cualquier evidencia de actividad judaizante, no importa

22 AzConA, Isabel, 384.

${ }^{23}$ Motis Dolader, Miguel Angel, La expulsión de los judios de Zaragoza (Zaragoza, Diputación General de Aragón, 1985), 40-42.

24 AzConA, Isabel, 384. 
cuán poco importante o remota en el tiempo, sitúa al individuo firmemente en el campo herético. Al adoptar el pensamiento inquisitorial estos historiadores han rechazado tomar en su valor nominal la evidencia del conflicto y el cambio generacionales, la creciente conciencia de los ritos y plegarias de parte de los conversos y la creciente fricción entre judíos y conversos respecto de una gran cantidad de temas. Para mostrar algunos de estos temas, me remitiré a la serie de artículos sobre los procesos de la Inquisición a los conversos de la localidad aragonesa de Teruel, de Manuel Sánchez Moya y J. Monasterio Aspiri ${ }^{25}$.

Algo que surge del registro del caso es la existencia de un significativo conflicto entre los conversos de la generación de la década de $1450 \mathrm{y}$ los de las décadas de 1470 y 1480 acerca de la pureza de sus prácticas judaicas. Al mismo tiempo hay evidencia de que a pesar de su apego al judaísmo, los jóvenes conversos estaban internalizando lentamente aspectos del cristianismo. Si tomamos a la familia Puxmija como nuestro primer ejemplo, la generación de 1450 está representada por el mercader Enojoan de Puxmija. Sánchez Moya y Aspiri describen el judaísmo de Enijoan como «químicamente puro», y parece haber escasas razones para dudar de esta descripción. Enojoan practicaba todas las ceremonias judías, observaba el Sabbath y llegó tan lejos como para tomar un rabino para instruir a sus hijos en los preceptos del judaísmo ${ }^{26}$. Francés, el hijo de Enojoan, estaba tan apelado al judaísmo como su padre, hasta el punto de tener reservado un asiento en la sinagoga y convertir su propia casa en una casa de plegarias a la cual muchos judíos podían ir a leer y rezar durante el Sabbath ${ }^{27}$.

Por otro lado, a pesar de su devoción al judaísmo, Francés de Puxmija conocía algunas plegarias cristianas básicas de memoria y solía decirlas entremezcladas con salmos cuando estaba viajando ${ }^{28}$. La tercera generación de esta familia está representada por Manuel de Puxmija. Manuel también observaba todos los preceptos judíos, pero evidentemente su padre encontraba que sus conocimientos eran deficientes y en una oportunidad lo llamó «ignorante» por no seguir los preceptos judíos tan fielmente como debía. Después de la muerte de su padre en el auto de fe de enero de 1486, Manuel se presentó ante la Inquisición para confesar sus actividades heréticas. Los inquisidores quedaron evidentemente im-

\footnotetext{
25 Sánchez Moya, Manuel, y Monasterio Aspial, Jasone, "Los judaizantes turolenses en el siglo XV", Sefarad 32, 33, 34 (1972-1973).

26 SÁnchez MOYa y MONASTERIO AspirI, "Los judaizantes", 111

27 Ibidem, 112.

28 Ibidem, 113.
} 
presionados por la sinceridad de Manuel, le ahorraron la hoguera, le permitieron abjurar y fue eventualmente liberado ${ }^{29}$.

Otro aspecto del fenómeno de asimilación entre generaciones se presenta si consideramos el grado de compromniso en el apoyo a la comunidad judía. En 1450, el converso Gil Ruiz el Viejo respetó fielmente una disposición del testamento de su padre que establecía que su heredero enviara a la sinagoga la provisión de un año de aceite y diera 200 sueldos anualmente para la dote de las judías pobres. Su hijo y heredero Gil de Gil Ruiz, sin embargo, aunque conocido por su ferviente judaísmo, no continuó la tradición familiar de las contribuciones, para la consternación de la comunidad judía ${ }^{30}$.

En algunos conversos, el judaísmo parece haber degenerado en mera superstición, en la creencia de que manteniendo algunas prácticas judaicas ellos o sus familias podían evitar la enfermedad u obtener otras ventajas. Se pueden observar trazas de este supersticioso judaísmo en la vida de Mosén Juan Ram, canon de la iglesia de Santa María. Aunque fue encontrado culpable de actividades judaizantes por la Inquisición, es claro que su conocimiento de los más elementales hechos del judaísmo era extremadamente deficiente. En algunas ocasiones tuvo que preguntarle al rabino Simuel la fecha del Yom Kippur para poder celebrarlo con su hermano Berenger. Fue Mosén Juan Ram el que ordenó a un sirviente quitar la landrecilla y desangrar atentamente el cuarto trasero de un animal recién muerto antes de cocinar y servir la carne, porque creía que si alguien comía la «landrecilla» podía volverse loco. Que el control del animal había perdido completamente su significado religioso para el canon Ram puede ser inferido claramente del hecho de que hizo todo esto abiertamente, cuando era cura párroco de Caudé, en frente de otros beneficiarios de la iglesia. Obviamente, si hubiera pensado que la revisión del animal tenía un contenido religioso, se hubiera tomado un trabajo más grande en esconderlo, al menos delante de los otros beneficiarios de la iglesia, que eran probablemente los más indicados para recordar el acto como algo inusual y posiblemente herético. De hecho, fue Francisco del Vicio, uno de dichos clérigos, quien denunció a Ram por dicha práctica ante la Inquisición, durante su proceso en $1485^{31}$.

Donosa Besante fue otra conversa cuya relación con el judaísmo estaba fuertemente teñida de superstición. Cuando su hijo se enfermó, in-

\footnotetext{
Ibidem, 115-116.

Ibidem, 125-8.

Ibidem, 326.
} 
mediatamente llamó a una mujer judía para que administrara la medicina. Cuando algo se perdía en su casa, llamaba a una judía que lo encontraba con algunos encantamientos. Después de tener una pesadilla, en 1477, Donosa fue a consultar al rabino Simuel, que le enseñó unas plegarias para recitar en dichas ocasiones. En 1481, cuando un judío que tenía fama de leer el futuro visitó Teruel, Donosa insistió en que el rabino Simuel le preguntara si sus dos hijas iban a casarse ${ }^{32}$. Donosa Besante fue encontrada culpable de judaización por el Sagrado Oficio y condenada a muerte, pero en vez de aceptar este veredicto como un juicio apropiado acerca de su posición religiosa, sería más apropiado ubicarla como siendo, tal como tantos otros creyentes de la Europa del siglo xv, judía y cristiana simultáneamente. Ignorantes de los preceptos fundamentales y de los principios morales subyacentes de su fe, la religión se había convertido en mero formalismo para ellos, no más que un conjunto de rituales, creencias y devociones seguidas con la esperanza de obtener algún beneficio personal, pero vacíos de contenido espiritual.

Al equiparar a los conversos y a los judíos, la tradición historiográfica más antigua comete el error de adoptar la perspectiva inquisitorial acerca de las prácticas religiosas de los conversos tomando el decreto de expuisión en su valor nominal. Lejos de ser un reflejo de la realidad de las relaciones cristiano-judías de fines del siglo xV, el decreto debe ser visto como un intento de racionalizar y justificar una derrota política masiva de la monarquía: el completo fracaso de su política de protección de las comunidades judías. Para llevar a cabo esto, el decreto buscó exagerar la amenaza representada por los judíos a la fe católica declarando que los judíos constantemente trataban de convertir a los «fieles cristianos» a sus «injuriosas creencias» ${ }^{33}$. Dejando de lado el significado del hecho de que el decreto habla de la amenaza a todos los «fieles cristianos» y no dice nada acerca de los conversos, la impresión que causa acerca de las relaciones entre conversos y judíos es claramente engañosa. Como he establecido en mi libro Inquisition and Society in the Kingdom of Valencia, recientemente publicado, “frialdad y reserva, más que el celoso galanteo» implicado por el decreto de expulsión caracterizó la actitud de los judíos del reino respecto de los conversos ${ }^{34}$. Por supuesto, tal como lo señala el decreto de expulsión, algunos judíos proveyeron de servicios religiosos

32 Ibidem, 136-137.

33 SuÁrez FERnández, Luis, Documentos acerca de la expulsión de los judíos (Valladolid, CSIC, 1964).

${ }_{34}$ HALICZER, Stephen, Inquisition and Society in the Kingdom of Valencia (Berkeley, University of California Press, 1990) 218. 
especializados a los conversos e inclusive deben haber dependido de ello para su subsistencia. Estos servicios incluían la provisión de comida cocida kosher, productos cortados ritualmente y matzoth para consumo individual. De cualquier modo, en estos casos estos servicios eran pagados - compensados de otra manera y no implicaban ningún afecto de parte del judío hacia el converso. En otro casos, especialmente en la provisión de entrenamiento religioso o consejo, el converso siempre parece estar yendo hacia el judío y no a la inversa, como parece indicar el decreto de expulsión. Fue el canon Juan Ram quien fue hacia el rabino Simuel para preguntar la fecha de Yom Kippur y no el rabino Simuel quien voluntariamente difundió la información. Cuando Castellana Gencor se casó con Pau Besante, sus nuevos parientes políticos llamaron a un maestro judío para instruirla en las ceremonias judías ${ }^{35}$.

En el momento presente, me parece a mí que una de las mayores e incumplidas tareas de la actual generación de historiadores es encarar plenamente el problema de las relaciones entre conversos y judíos en la época de la expulsión. Una manera de hacerlo es analizar sistemáticamente los registros de la Inquisición de antes de 1530, donde hay una considerable información acerca de la interacción diaria entre judios y conversos en los lugares donde coexistieron.

Un análisis detallado de los procesos conduce a una percepción de los modelos de interacción e intercambio que indican relaciones de dominador-dominado, de inferioridad-superioridad y el fracaso de la comunicación en las relaciones sociales entre los dos grupos. Si tomamos como ejemplo la evidencia contenida en el registro del proceso de María del Río, ésta intercambió y recibió regalos con la judía Jumilla y con la pareja judía formada por Simuel y Estrella Catorce. María recibió matzoth de parte de Jumilla durante Pascuas, y cuando la festividad terminó, le envió una pequeña canasta con pan, hierbas, huevos duros y una jarra de miel. Cuando Estrella se casó con Simuel fue con él a visitar a María y recibió un florín para comprar un adorno para el pelo. Después de su casamiento, cocinó comida kosher para María, que correspondió regalando a sus dos hijos ropas que había pertenecido a su difunto marido y que los niños «usaron con orgullo». La tarea del historiador, cuando enfrentar este tipo de evidencia, es hacer lo que trató de realizar Marcel Mauss en su Essais sur le don: entender el significado social de este intercambio de objetos. En todos los intercambios de regalos «hay una serie de derechos y deberes acerca del consumo y la devolución que coexisten con los derechos y los deberes del dar y del recibir» ${ }^{36}$. En este

SÁNCHez MOYa y Monasterio AspiRI, "Los Judaizantes», 31, 136.

Mauss, Marcel, The Gift (Glencoe, Illinois, The Free Press, 1954) 11 
caso tenemos un intercambio que es manifiestamente desigual. Desde un punto de vista material, la canasta de alimentos superaba mucho el valor de las piezas de pan, y la comida kosher era menos valiosa que las prendas de ropa usada, a juzgar por la reacción de los hijos de Estrella. Desde un punto de vista espiritual, sin embargo, el regalo de comida kosher y de matzoth era mucho más valioso y no podía compensarse con ningún retorno material. Tanto el pan cuanto la comida habían sido sacralizados y sólo por medio de ellos podían los conversos celebrar apropiadamente los días sagrados judíos. Pero como nos recuerda Mauss, «el regalo que no ha sido retribuido deshayrarquiza al hombre que lo acepta» mientras que «la caridad yerre al que lo recibe» ${ }^{37}$. Los intercambios entre judíos y conversos sólo podían humillar y herir, nunca satisfacer o compensar, pues los conversos ya no podían retribuir con objetos debidamente sacralizados y los judíos iban a resentirse inevitablemente por la riqueza de las personas que habían renunciado a Dios. Cada regalo se convirtió en lo que Mauss llama «un regalo funesto, el presente que se convierte en veneno", un veneno que inevitablemente corroería y amargaría las relaciones sociales entre judíos y conversos ${ }^{38}$.

Mi análisis de este aparentemente simple y poco complicado intercambio de regalos entre judíos y conversos trata de ilustrar el hecho de que los registros de la Inquisición pueden ser utilizados de manera no tradicional para que revelen significativos aspectos de las relaciones sociales hasta ahora incomprendidas o ignoradas. La aplicación de las perspectivas de la sociología o la antropología al estudio de las relaciones sociales entre judíos, conversos y viejos cristianos en los años críticos que culminaron en 1492 debe conducir inevitablemente a una comprensión más profunda de la expulsión final. Al mismo tiempo, para alcanzar un nivel más profundo de análisis, los historiadores deben estar dispuestos a examinar sus propios supuestos y desprenderse de prejuicios que puedan inhibir sus evaluaciones. Judíos, conversos y viejos cristianos vivieron, en las décadas anteriores a 1492, en un mundo que cambiaba rápidamente. Todo era posible, desde la continuación de alguna forma de convivencia, de la cual siguieron gozando los moros de Aragón hasta 1526, hasta la expulsión lisa y llana. El hecho de que se eligiera la última posibilidad no fue una decisión predeterminada y los factores políticos, sociales y culturales que condujeron a ella están todavía lejos de haber sido completamente comprendidos.

37 Ibidem, 63.

38 Ibidem, 62. 